\title{
COMPORTAMENTO DE MILHO HÍBRIDO PARA SILAGEM EM DIFERENTES CONDIÇÕES DE SUCESSÃO DE CULTURAS NO MUNICÍPIO DE UMUARAMA-PR
}

\author{
Carlos Magno Quirino de Farias ${ }^{1}$ \\ Valmir Fernandes ${ }^{2}$ \\ Simone de Melo Santana Gomes ${ }^{3}$ \\ Adão Izidoro Junior ${ }^{4}$ \\ Sephora Serrano Baldisera ${ }^{5}$ \\ Raiane Pereira Schwengber ${ }^{6}$ \\ Gesivaldo Alves do Nascimento
}

FARIAS, C. M. Q.; FERNANDES, V.; SANTANA-GOMES, S. M.; IZIDORO JUNIOR, A.; BALDISERA, S. S.; SCHWENGBER, R. P.; NASCIMENTO, G. A. Comportamento de milho híbrido para silagem em diferentes condições de sucessão de culturas no município de Umuarama - PR. Arq. Ciênc. Vet. Zool. UNIPAR, Umuarama, v. 19, n. 4, p. 227-230, out./dez. 2016.

RESUMO: O objetivo do trabalho foi avaliar o comportamento do milho híbrido para silagem em diferentes condições de sucessão de culturas no município de Umuarama - PR. O experimento foi realizado em duas diferentes áreas da fazenda experimental da Universidade Paranaense - UNIPAR, no referido município. Na área 1 cultivou-se o milho em sucessão à cana-de-açúcar e na área 2, em sucessão à pastagem do gênero Brachiaria. O experimento foi conduzido no período de dezembro/2014 a abril/2015. Utilizou-se o milho híbrido 2B688 PW, cujos tratos culturais foram realizados conforme a necessidade da cultura. Após 78 dias da semeadura, foram amostradas, aleatoriamente, 19 parcelas de $8 \mathrm{~m}^{2}$ em cada área, onde se avaliou altura de plantas e de inserção de espiga, comprimento e diâmetro de espiga. Não foram verificadas diferenças significativas entre os tratamentos para todas as variáveis analisadas, evidenciando que a cultura do milho apresentou as mesmas respostas quando cultivada em sucessão à cana ou à pastagem de Brachiaria.

PALAVRAS-CHAVE: Brachiaria. Cana-de-açúcar. Noroeste do Paraná. Pastagem.

\section{HYBRID MAIZE FOR SILAGE IN DIFFERENT CROP SUCCESSION CONDITIONS IN THE CITY OF UMUARAMA-PR}

\begin{abstract}
The purpose of this study was to evaluate the behavior of hybrid maize for silage in different crop succession conditions in the city of Umuarama - PR in two different areas. The experiment was performed at the experimental farm at Universidade Paranaense - UNIPAR in the aforementioned city. In area 1, maize was grown after sugarcane, while in area 2 it was grown after pasture with Brachiaria. The experiment was carried out from December/2014 to April/2015. Hybrid maize 2B688 PW was used, with cultural traits performed according to the crop needs. Seventy-eight days after sowing, 19 plots measuring $8 \mathrm{~m}^{2}$ each were randomly chosen and analyzed, assessing plant height and spike insertion, as well as length and spike diameter. There were no significant differences between treatments for all variables analyzed, therefore, it can be concluded that maize crop presented the same responses when grown in succession to sugarcane or to Brachiaria pasture.

KEYWORDS: Brachiaria. Northwestern Paraná. Pasture. Sugarcane.

\section{COMPORTAMIENTO DE MAÍZ HÍBRIDO PARA ENSILAJE EN DIFERENTES CONDICIONES DE SUCESIÓN DE CULTIVOS EN EL MUNICIPIO UMUARAMA-PR}

RESUMEN: El objetivo de este estudio ha sido evaluar el comportamiento del maíz híbrido para ensilaje en diferentes condiciones de sucesión de culturas en la ciudad de Umuarama - PR. El experimento se llevó a cabo en dos áreas diferentes de la granja experimental de la Universidad Paranaense - Unipar, en el referido municipio. En el área 1 se ha cultivado maíz en sucesión a la caña de azúcar y en el área 2, en sucesión al pasto del género Brachiaria. El experimento se llevó a cabo en el periodo de diciembre/2014 a abril/2015. Se utilizó el maíz híbrido $2 \mathrm{~B} 688 \mathrm{PW}$, cuyas prácticas culturales se realizaron como las necesidades de los cultivos. Después de 78 días de la siembra, se tomaron muestras al azar, 19 parcelas de $8 \mathrm{~m}^{2}$ en cada área, que evaluó altura de las plantas y la inserción de mazorca, longitud y diámetro de mazorca. No se encontraron diferencias significativas entre los tratamientos para todas las variables, mostrando que el maíz presentó las mismas respuestas cuando cultivado en sucesión a la caña o al pasto de Brachiaria.

PALABRAS CLAVE: Brachiaria. Caña de azúcar. Noroeste de Paraná. Pastizales.

DOI: https://doi.org/10.25110/arqvet.v19i4.2016.6101

${ }^{1}$ Engenheiro Agrônomo, Mestre em Biotecnologia Aplicada à Agricultura, Umuarama, PR, Brasil. E-mail: carlosm agro@hotmail.com

${ }^{2}$ Médico Veterinário, Especialista em Clínica de Ruminantes, Universidade Paranaense, Umuarama, PR, Brasil. E-mail: veteagro@gmail.com

3Programa de Pós-graduação em Biotecnologia Aplicada à Agricultura, Universidade Paranaense, Umuarama, PR, Brasil. E-mail: simonemelo@unipar.br ${ }^{4}$ Graduando em Engenharia Agronômica, Universidade Paranaense, Umuarama, PR, Brasil. E-mail: adao_1995@hotmail.com

${ }^{5}$ Tecnóloga em Estética e Cosmética, Mestranda em Biotecnologia Aplicada à Agricultura, Universidade Paranaense, Umuarama, PR, Brasil. E-mail: sephorabaldisera@gmail.com

${ }^{6}$ Graduanda em Engenharia Agronômica, Universidade Paranaense, Umuarama, PR, Brasil. E-mail: raiane_schwengber@hotmail.com

${ }^{7}$ Engenheiro Agrônomo, Mestre em Ciências Agrárias, Universidade Estadual de Maringá, Campus Regional de Umuarama, Umuarama, PR, Brasil. E-mail: val_1108@hotmail.com 


\section{Introdução}

O Brasil é o terceiro maior produtor de grãos de milho (Zea mays L.) no ranking mundial, sendo que 37\% da área cultivada no país é dedicada à cultura (MELO, 2014). No Paraná, o milho é o grão que mais ganhará área plantada na safra 2016/2017. A cultura avançou $17 \%$, passando de 413.775 hectares na safra passada para 484.940 hectares na safra 2016/2017. Já a expectativa de produção avança em torno de $28 \%$, devido à rentabilidade do grão, que representa o dobro da soja (Glycine max (L.) Merr.), cuja produção esperada é de 4,24 milhões de toneladas, quase um milhão a mais sobre a safra anterior, que rendeu 3,3 milhões durante a primeira safra (COOPERATIVA AGROINDUSTRIAL BOM JESUS, 2016).

No país, o milho é a gramínea mais utilizada na produção de silagem, em virtude da facilidade de cultivo, alta produção de massa, facilidade de fermentação dentro do silo, bom valor energético e alto consumo pelos animais (PEREIRA, 2004). A silagem é um produto resultante de um processo específico de fermentação anaeróbica (anaerobiose) que induz a acidificação do material vegetal verde, impedindo assim a degradação e mantendo as propriedades nutricionais do produto, permitindo assim seu armazenamento por longos períodos e que quando bem preparada, apresenta características nutritivas semelhantes à forrageira in natura que lhe deu origem, garantindo consumo e bons índices de produtividade (LOPES; NOVAES; CARNEIRO, 2004).

A escolha do híbrido para a produção da mesma é de extrema importância para que o produtor obtenha um produto de qualidade que resulte em lucros satisfatórios no desenvolvimento da atividade pecuária (LUPATINI et al., 2004). Como exemplo de matéria-prima muito utilizada, têm-se o milho híbrido 2B688 PW, devido seu grande valor nutricional e alta produção de matéria seca por hectare, além do baixo custo de produção, colheita simplificada e facilidade de armazenamento, tornando o cultivo do milho uma das melhores opções para o produtor que necessita de armazenamento de alimento para seu rebanho em períodos climáticos instáveis (PÔSSAS et al., 2015).

Sendo assim, o objetivo do trabalho foi avaliar o comportamento do milho híbrido, para produção de silagem em duas áreas no município de Umuarama, cultivadas previamente com cana-de-açúcar e pastagem.

\section{Material e Métodos}

O experimento foi conduzido em duas áreas distintas da Fazenda Experimental da Universidade Paranaense - UNIPAR, no município de Umuarama, PR, em sistema de cultivo convencional, na safra 2014/2015, em sucessão à pastagem de Brachiaria spp. (Área 1) e cana-de-açúcar (Área 2).

O experimento foi conduzido sob Latossolo Vermelho Distrófico (EMBRAPA, 2013), de textura arenosa, caracterizado quimicamente, conforme Tabela 1. Os resultados foram utilizados para recomendações de calagem e adubação.

Em ambas as áreas foram realizados o preparo mecânico do solo com operações de grade pesada, e calagem para elevar a saturação de base a 70\%, totalizando 2,5 t ha- ${ }^{1}$ de calcário dolomítico, distribuído a lanço, com um distribuidor de arrasto, entre um e dois meses antes da semeadura. Quanto à adubação, aplicou-se $350 \mathrm{~kg}$ ha- ${ }^{1}$ do formulado 0430-10 na base, e após 20 dias da semeadura, $100 \mathrm{~kg}$ de ureia em cobertura.

Tabela 1: Análise química do solo das áreas 1 e 2 da fazenda experimental da UNIPAR localizada no município de Umuarama -PR, na profundidade de 0,0 a $10 \mathrm{~cm}$

\begin{tabular}{ccccccc}
\hline Local & $\mathrm{pH}$ & $\mathrm{V}(\%)$ & $\mathrm{C}\left(\mathrm{g} \mathrm{dm}^{-3}\right)$ & $\mathrm{P}_{2} \mathrm{O}_{5}\left(\mathrm{mg} \mathrm{dm}^{-3}\right)$ & $\mathrm{K}_{2} \mathrm{O}\left(\mathrm{cmol} \mathrm{dm}^{-3}\right)$ & $\mathrm{CTC}\left(\mathrm{cmol} \mathrm{dm}^{-3}\right)$ \\
\hline Área 1 & 5,4 & 41,8 & 4,9 & 18,3 & 0,1 & 6,8 \\
Área 2 & 4,9 & 35,0 & 3,5 & 4,6 & 0,1 & 5,7 \\
\hline pH - Teor de acidez do solo; $\mathrm{V}$ - Saturação por Bases; C - Carbono; P - Fósforo; K - Potássio; CTC - Capacidade de Troca de Cátions.
\end{tabular}

Como material vegetal, utilizou-se o milho híbrido 2B688 PW, semeado em dezembro de 2014 (Área 2) e em janeiro de 2015 (Área 1). O espaçamento entre linhas e entre plantas foi, respectivamente, 90 e $20 \mathrm{~cm}$, com $0,5 \mathrm{~cm}$ de profundidade, para uma população de 55 mil plantas por hectare.

Durante o desenvolvimento da cultura efetuou-se o controle de pragas, dentre elas, a lagarta do cartucho (Spodoptera frugiperda), com o inseticida Espinosade ${ }^{1}$, conforme recomendação e necessidade da cultura. A precipitação média do período de condução do experimento foi de $142 \mathrm{~mm}$.

Após 78 dias, aproximadamente, da semeadura, realizou-se as avaliações das plantas do experimento, delimitando-se, aleatoriamente, 19 parcelas de $8 \mathrm{~m}^{2}$ cada, nas respectivas áreas experimentais.

As variáveis analisadas foram: altura de plantas (metro) e de inserção de espiga (centímetro), comprimento e diâmetro de espiga (centímetro). Para as avaliações, aferiu-se quatro plantas das fileiras centrais, descartando-se as bordaduras.

Os dados foram comparados pelo teste $\mathrm{T}$ independente ao nível de $5 \%$ de probabilidade.

\section{Resultados e Discussão}

De acordo com os resultados da tabela 2, os dados não foram significativos, demonstrando ausência de interferência das culturas antecessoras sobre as variáveis analisadas no milho.

Segundo DowAgroSciences (2009), o milho 2B688 é um híbrido de porte médio, com altura média por planta de $210 \mathrm{~cm}$ e altura média da inserção de espigas de $115 \mathrm{~cm}$, os quais se aproximam dos dados deste experimento (Tabela 2).

${ }^{8}$ TRACER $^{\circledR}$, Dow AgroScienses, Habor Beach - Michigan 48441 - Estados Unidos. 
Tabela 2: Altura de planta e de inserção de espiga, comprimento (CE) e diâmetro da espiga (DE) do milho 2B688PW após 78 dias de cultivo no município de Umuarama - PR, safra 2014/2015

\begin{tabular}{ccccc}
\hline Local & Altura de planta & Altura de inserção de espiga & CE & DE \\
\cline { 2 - 5 } Área 1 & \multicolumn{4}{c}{ Cm } \\
Área 2 & $213,00^{\text {ns }}$ & $860,00^{\text {ns }}$ & $16,24^{\text {ns }}$ & $4,59^{\text {ns }}$ \\
\hline CV (\%) & 230,00 & 940,00 & 16,58 & 4,10 \\
\hline CV & 7,85 & 17,35 & 6,96 & 12,95 \\
\hline
\end{tabular}

$\overline{\mathrm{CV}}=$ Coeficiente de variação; ns: não significativo.

Noce et al. (2008), avaliando o comportamento do milho em sucessão a diferentes plantas de cobertura, observaram que a altura da planta foi influenciada pela palha deixada pela cultura anterior. Segundo os autores este efeito foi provocado pelo maior volume de palha cobrindo o solo, induzindo a uma maior elongação do caule das plantas de milho, na tentativa de romper a camada de palha. Entretanto, este comportamento não foi observado nas condições que foram desenvolvidas no presente trabalho, mostrando assim que a quantidade de palha produzida pela cultura anterior não influenciou a altura de plantas (Tabela 2).

De acordo com Silva et al. (2006), a altura de planta é um parâmetro que determina o grau de desenvolvimento da cultura e que tem correlação positiva com a produtividade, provavelmente por sofrer menos estresse durante o seu desenvolvimento, acumulando maiores quantidades de reservas no colmo.

Castoldi et al. (2007), avaliando o desempenho do milho para produção de silagem de planta inteira em diferentes sistemas de culturas, plantio direto (PD) ou plantio convencional (PC), também não verificaram diferenças significativas entre os sistemas para altura de planta, número de folhas e diâmetro de colmo. Por sua vez, Noce et al. (2008) obtiveram menor diâmetro de colmo das plantas de milho, em sucessão à cobertura de milheto, em relação àquelas desenvolvidas nas coberturas de sorgo e braquiária.

Em outros trabalhos de sucessão, observaram que a sequência de culturas soja/pousio/soja, soja/milheto/soja, soja/crotalária/soja ou o uso de uma safra de soja na reforma do canavial manteve os níveis de fertilidade em um Latossolo Vermelho (FERNANDES; CORA; MARCELO, 2012). Em contrapartida, Monquero et al. (2008) constatou efeito supressor de Crotalaria juncea L. sobre as gramíneas Brachiaria decumbens Stapf. e Panicum maximum Jacq. Isso se deve à elevada biomassa produzida pela leguminosa, que impediu o desenvolvimento das mesmas.

Com base nos resultados apresentados, a sucessão de culturas com espécies de mesma família botânica proporcionou ao milho um desenvolvimento vegetativo normal, independente da cultura antecessora (cana ou pastagem de braquiária), contribuindo para a produção de forragem.

\section{Conclusão}

O cultivo de milho híbrido 2B688 PW em sucessão à cana-de-açúcar e/ou pastagem no município de Umuarama não influenciou significativamente a altura de plantas e inserção de espiga, comprimento e diâmetro de espiga, porém, em ambas as condições de cultivo, as plantas demonstraram desenvolvimento vegetativo normal.

\section{Referências}

CASTOLDI, G et al. Parâmetros fitométricos da cultura do milho sob diferentes sistemas de produção nas fases de silagem de planta inteira e grão úmido. In: CONGRESSO BRASILEIRO DE CIÊNCIA DO SOLO, 31., 2007,Gramado.Anais... Gramado: UFPel, CD-ROM.

\section{COOPERATIVA AGROINDUSTRIAL BOM JESUS.} Área da primeira safra de milho deve crescer $17 \%$ no Paraná. Disponível em: <http://www.bj.coop.br/singlepost $/ 2016 / 09 / 02 / \%$ C3\%81 rea-da-primeira-safra-de-milhodeve-crescer-17-no-Paran\%C3\%A1>. Acesso em: $26 \mathrm{dez}$. 2016.

\section{DOWAGROSCIENCES. Sementes e Biotecnologia.} Tecnologia para o Brasil produzir mais. Rio de Janeiro: EMBRAPA, 2009. (Circular técnica).

\section{EMPRESA BRASILEIRA DE PESQUISA} AGROPECUÁRIA - EMBRAPA. Sistema brasileiro de classificação de solos. 3.ed. EMBRAPA, Brasília, 2013. $353 \mathrm{p}$.

FERNANDES, C.; CORA, J. E.; MARCELO, A. V. Soil uses in the sugarcane fallow period to improve chemical and physical properties of two Latosols (oxisols). Revista Brasileira de Ciência do Solo, Viçosa, v. 36, n. 1, p. 283294, 2012.

LOPES, F. C. F. F.; NOVAES, L. P.; CARNEIRO, J. C.Silagens: oportunidades e pontos críticos. Juiz de Fora: Embrapa Gado de Leite, 2004. 10 p. (Embrapa Gado de Leite. Comunicado Técnico, 43).

LUPATINI, G.C. et al. Avaliação do desempenho agronômico de híbridos de milho (Zea mays L.) para produção de silagem. Revista Brasileira Milho e Sorgo, Sete Lagoas, v.3, n.2, p.193-203, 2004.

MELO, H. F. Adubação nitrogenada e inoculações de sementes com Azospirillum brasilense na cultura do milho. 2014, 36p. (Trabalho de Conclusão de Curso Engenharia Agronômica) UFSC - Universidade Federal de Santa Catarina, Curitibanos, 2014.

MONQUERO, P. A et al. Mapas de infestação de plantas daninhas em diferentes sistemas de colheita da cana-deaçúcar. Planta Daninha, Viçosa, v. 26, n. 1, p. 47-55, 2008. 
NOCE, M. A. et al. Influência da palhada de gramíneas forrageiras sobre o desenvolvimento da planta de milho e das plantas daninhas. Revista Brasileira de Milho e Sorgo, v.7, p.265-278, 2008.

PEREIRA, R. C. et al.Efeitos da inclusão de forragem de Leucena(Leucaena leucocephala (Lam.) DeWit) na qualidade da silagem de milho (Zea mays L.). Revista Ciência e Agrotecnologia, Lavras, v.28, n. 4, p. 924-930, 2004.

PÔSSAS, F. P. et al. Cinética de fermentação ruminal das silagens de três híbridos de milho comerciais em diferentes estádios de maturação. Arquivo Brasileiro de Medicina Veterinária e Zootecnia, Belo Horizonte, v. 67, n. 1, p. 159-165, 2015.

SILVA, D. A. et al. Culturas antecessoras e adubação nitrogenada na cultura do milho, em sistema plantio direto. Revista Brasileira de Milho e Sorgo, Dourados, v.5, p.7588, 2006.

Recebido em: 20.11.2016

Aceito em:27.12.2016 